This paper is published in the open archive of Mid Sweden University

DIVA http://miun.diva-portal.org

with permission of the publisher

Citation for the peer-reviewed published paper:

Pettersson G, Wågberg L, Höglund H. The use of polyelectrolyte multilayers of cationic starch and CMC to enhance strength properties of papers formed from mixtures of unbleached chemical pulp and CTMP : Part I. ; Nordic Pulp \& Paper Research Journal. 2006;21(1):115-121.

URL to article at publishers site:

http://dx.doi.org/10.3183/NPPRJ-2006-21-01-p115-121 


\title{
The use of polyelectrolyte multilayers of cationic starch and CMC to enhance strength properties of papers formed from mixtures of unbleached chemical pulp and CTMP. Part I
}

\author{
Gunilla Pettersson and Hans Höglund, Mid Sweden University, Sundsvall, Lars Wågberg, Royal Institute of Technology, KTH, Stockholm, Sweden
}

KEYWORDS: Adsorption, Interactions, Mechanical properties, Multilayer, Polyelectrolytes, Surfaces

SUMMARY: The construction of alternating multilayers of cationic potato starch and anionic carboxymethylcellulose (CMC) was investigated in two parts. In the first part, stagnation point adsorption reflectometry (SPAR) showed that the chosen chemicals formed polyelectrolyte multilayers (PEM) upon adsorption to the silicon oxide surface. This was in accordance with earlier work. The chosen polyelectrolytes adsorbed to similar extents on the silicon oxide surface and recharged the surface enough to allow for adsorption of a consecutive layer. In the second part, the multilayer concept was tested on $80 / 20$, $20 / 80 \%$ of total in mixture of mixed spruce CTMP and bleached chemical pulp in order to enhance the sheet strength properties of a typical packaging board furnish.. The multilayers yielded a significant improvement in Scott Bond values and tensile index and a marginal improvement in tensile stiffness index. The Scott Bond values were improved more than $150 \%$ for papers prepared from a furnish consisting of $80 \%$ spruce CTMP and $20 \%$ chemical pulp. Polyelectrolyte multilayers treatment also led to a slight densification of the sheets, but the polyelectrolyte multilayers treatment resulted in a more favourable density/strength relationship than that achieved with a change in the amount of chemical pulp.

\section{ADDRESSES OF THE AUTHORS: Gunilla Pettersson \\ (gunilla.pettersson@miun.se) and Hans Höglund, (hans.hoglund@miun.se): Mid Sweden University, Department of Natural Sciences, Fibre Science Communication Network, FSCN, SE-851 70 Sundsvall, Sweden Lars Wågberg (wagberg@polymer.kth.se): Royal Institute of Technology, KTH, Department of Fibre and Polymer Technology, Division of Fibre Technology, SE-100 44 Stockholm, Sweden. Corresponding author: Gunilla Pettersson}

There is an increasing interest in using mechanical and chemimechanical pulps with a high freeness in order to produce a bulkier sheet and hence a higher structural stiffness of the paper (Niskanen et al. 1998). In order to reach the maximum effect, the mechanical and chemimechanical pulp should contain a high fibre fraction with long and intact fibres and as little fines material as possible (Sundholm 1999). Unfortunately, pulps containing long stiff fibres also exhibit a poor ability to produce sufficient out-of-plane mechanical properties of the paper. The desired freeness of the chemimechanical pulps is therefore always a compromise between the bulk-increasing ability and the ability to increase the outof-plane strength properties of the paper made from these fibres. An alternative route for producing an optimum structure would be to treat a high freeness pulp with chemical additives to improve the out-of-plane mechanical properties, for the papers produced from these pulps.
The dominating treatment for improving paper strength is the addition of cationic starch to the fibres (Roberts 1996). Considerable work has also been conducted regarding adsorption of cationic starch on bleached chemical pulps (Marton 1980, Hedborg and Lindström 1993). This knowledge can naturally also be extended to improving the strength of papers from chemimechanical pulps. However, difficulties exist in adsorbing high amounts of starch to chemimechanical pulps containing a low amount of fines and high concentrations of dissolved and colloidal material (Wågberg and Kolar 1996).

Therefore it is of interest to develop alternative treatments, such as the polyelectrolyte multilayer treatment (PEM) concept (Decher 1997). This is a relatively new method for modifying a surface, whereby a charged surface is consecutively treated with oppositely charged polyelectrolytes. This layer-by-layer technique has become popular over the last ten years, several applications are available all the way from modification of surface charge (Decher and Schlenoff 2003) to preparation of new sensor technology (Sun et al. 1996). Applying this technique to fibres has also been used to improve paper strength (Wågberg and Forsberg 1998, Wågberg et al. 2002), making it possible to tailor the surface with high amounts of additives to meet certain end-use properties. Wågberg et al. (2002) used polyallylamine (PAH) and polyacrylic acid (PAA), but because of their high cost they are limited in the papermaking industry. With this as a background, it is of considerable interest to investigate if the polyelectrolyte multilayers technique could be used to improve paper strength using two already well known polyelectrolytes for the papermaking industry, starch and CMC. CMC was chosen as it is commonly used in tissue manufacturing as a charge controller to retain a high amount of cationic wet strength resin in the sheet. CMC has furthermore been used as the anionic component for polyelectrolyte complex formation in tissue manufacturing (Reynolds 1980). It is also known that CMC will give a considerable dry strength improvement together with PAE (polyaminoamide epichlorohydrine) resins (Reynolds 1980).

The polyelectrolyte multilayers concept could preferably be applied to furnish typical of a centre ply in a liquid packaging board, i.e., a mixture of chemimechanical pulp (CTMP) and unbleached chemical pulp, to both get high bulk from the CTMP and improve the paper strength with the polyelectrolyte multilayers.

Results are presented from experiments conducted to correlate the properties of the multilayer to the obtained sheet strength. Also, the possibility to build up polyelectrolyte multilayers with these low charge density polyelectrolytes on silica surfaces with a reflectometry was 
investigated. Stagnation Point Adsorption Reflectometry (SPAR) (Dijt et al. 1990) is very useful for predicting adsorption of polyelectrolytes typically used in the pulp and paper industry (Wågberg and Nygren 1999, Wågberg et al. 2004). The formation of polyelectrolyte multilayers of low charge density cationic starch and anionic CMC was also investigated for a direct determination of the amount of polyelectrolytes that could be adsorbed to the fibres.

\section{Experimental}

\section{Materials}

Pulps. The unbleached chemical softwood spruce/pine pulps were obtained from Stora Enso, Skoghall, Sweden. The chemical pulp had been cooked to a kappa number of 32 and was washed with distilled water before use. It was then circulation refined in a Voith Sulzer LR1 laboratory refiner at $4 \%$ consistency under the following conditions: conical refiner fillings, $3 \mathrm{~mm}$ bar width, 60 degree cutting angle, a flow rate of $100 \mathrm{lit} / \mathrm{min}$, a rotational speed of $2000 \mathrm{rpm}$, and with a constant -specific edge load of $3.5 \mathrm{Ws} / \mathrm{m}$. Fibres refined to $22 \mathrm{SR}$ were chosen for the majority of the experiments.

The unbleached chemimechanical pulp, CTMP, with a freeness of $450 \mathrm{ml}$ and a SR number of $\sim 28$ from spruce was delivered from Stora Enso, Skoghall, Sweden. The pulp was hot disintegrated and washed with distilled water before use.

Silicon wafers. Silicon wafers, from Memc Electronics Materials, Novara, Italy, with a top silicon oxide layer were used as the substrate for the SPAR measurements. The silicon oxide top layer was obtained by oxidising the silicon wafer at atmospheric pressure in an oven at 1000 ${ }^{\circ} \mathrm{C}$ for 30 min (Dijt et al., 1990). The wafer was taken out and cooled in air. It was then cut into smaller pieces with a diamond knife and stored in a sealed Petri dish.

Chemicals. A cationic starch (CS) was supplied from Lyckeby Stärkelsen, Sweden, for use in the polyelectrolyte multilayers technique. The cationic starch used in this investigation had a degree of substitution (D.S.) of 0.065 , corresponding to a charge density of $0.38 \mathrm{meq} . / \mathrm{g}$. The cationic starch was laboratory cooked by heating a $1 \mathrm{~g} / \mathrm{l}$ starch slurry to $95{ }^{\circ} \mathrm{C}$ and maintaining this temperature for $30 \mathrm{~min}$, after which the starch solution was cooled down under ambient conditions. The degree of starch gelation was studied with light microscopy. Fresh solutions of starch needed to be prepared every day and stored for a maximum of $8 \mathrm{~h}$ in order to avoid the influence of starch degradation.

The other polyelectrolyte used for the multilayers was CMC with high purity (>99.5\%) Cekol $50000 \mathrm{G}$ that was obtained as a powder from Noviant, Finland. The degree of substitution in the product was 0.8 , and molecular weight, according to the manufacturer, was around 90 000.The charge density of CMC was $3.67 \mathrm{meq} . \mathrm{g}$. The $\mathrm{CMC}$ was dissolved in deionized water 12 hours before use at a concentration of $1 \mathrm{~g} / \mathrm{l}$.

Potassium polyvinyl sulphate (KPVS) from Wako Pure Chem. Ltd., Japan, and 3.6-ionene, Polybrene, from
Sigma Aldrich were used in the polyelectrolyte titrations to determine the fibre charge. Both polyelectrolytes were delivered as powders and used without further purification.

The surface charge determination was made with a high molecular mass polyDADMAC, Alcofix 109, supplied by Ciba Speciality Chemicals. Ultrafiltration was used to remove the low molecular mass fraction of the polymer in order to make it suitable for surface charge determinations. The theoretical charge density of the polyDADMAC was 6.19 meq./g. The molecular mass of the filtered polymer was $1.2 \cdot 10^{6}$, as determined by size exclusion chromatography (Swerin and Wågberg 1994). Hydrochloric acid, sodium hydroxide, and sodium chloride were all of analytical grade. All chemicals were used without further purification and dissolved in and diluted with MilliQ-water.

\section{Method}

Stagnation Point Adsorption Reflectometry (SPAR). The detailed build-up of polyelectrolyte multilayers was studied with a reflectometer according to a previously outlined method (Dijt et al. 1990, 1994, Hoogeveen et al. 1996, Dabros and van de Ven 1983). A linearly polarised laser beam is reflected from the solid surface in a measurement chamber, after which it is split into two components: one parallel and one perpendicular to the plane of incidence. The intensities of these components $\left(I_{p}\right.$ and $\left.I_{s}\right)$ are measured by photodiodes. An analogue divider gives the signal:

$$
\boldsymbol{S}=\frac{\boldsymbol{I}_{p}}{\boldsymbol{I}_{s}}=\boldsymbol{f}\left(\frac{\boldsymbol{R}_{p}}{\boldsymbol{R}_{s}}\right)
$$

where $R$ is reflectance, and $p$ and s denote parallel and perpendicular components respectively. Any build-up of material with a refractive index different from that of the collector surface changes the polarisation of the reflected beam.

The optical response of the layer of adsorbed polyelectrolyte was analysed using the method described by Dijt et al. (1994). A sensitivity factor (As) was calculated using the following parameters: the angle of incidence, the refractive index increment of the polyelectrolyte solution, the thickness of the oxide layer, and refractive indices of all the phases. The amount adsorbed, $\Gamma$, is given as (in $\mathrm{mg} / \mathrm{m}^{2}$ ):

$$
\Gamma=\frac{\Delta S}{S_{o}} \cdot \frac{1}{A}
$$

where $\Delta S$ is the change in the reflectometer signal upon adsorption and $\mathrm{S}_{\mathrm{o}}$ is the value of the signal before adsorption.

From the change of $\Delta S$, upon polyelectrolyte adsorption, it is possible to calculate an adsorbed amount, $\Gamma$, using a four-layer optical model according to equation (2). The $d n / d c$-values used for the cationic starch and the CMC are $0.142 \mathrm{ml} / \mathrm{g}$ (Galinsky and Burchard 1997) and $0.151 \mathrm{ml} / \mathrm{g}$ (Gärdlund et al. 2003) respectively. S-values normalised by the $d n / d c$ values can be directly translated as an adsorbed amount. 
Adsorption isotherms. A streaming current detector from Mütek Analytic GmbH (Bley and Kastner, 1992) was used to determine the adsorption isotherms for the formation of PEM on fibres. Anionic solutions were titrated with polybrene, whereas cationic solutions were titrated with KPVS to the isoelectric end point. The charge of the solution was thereafter determined by the amount of either the cationic or anionic charges added per litre sample. Adsorption measurements were performed with a $100 \mathrm{ml}$ solution of fibres at a concentration of $5 \mathrm{~g} / 1$ in $0.01 \mathrm{M} \mathrm{NaCl}$ at $\mathrm{pH} 6$, representing normal conditions for paper production. Adsorption isotherms were made from a series of at least five samples, each sample having a different amount of polyelectrolyte added. In order to determine equilibrium adsorption for the first layer, the solution was stirred and the $\mathrm{pH}$ was fixed at 6.0 by $\mathrm{HCl}$ addition. Starch was added in excess to five pulp samples. The samples were then stirred for 10 minutes to reach adsorption equilibrium, after which the suspensions were filtered in a Büchner funnel fitted with Munktell No. 3 filter paper. Polyelectrolyte titration of the filtrate was used to determine the amount of polyelectrolyte remaining in solution, which provided individual adsorption isotherms for each layer. Further layers were adsorbed in a similar manner after washing the fibres with distilled water. Titrations were carried out with the appropriate, i.e., oppositely charged, polyelectrolyte depending on the adsorbing polyelectrolyte.

Charge determination. The total charge was determined by conductometric titration with $\mathrm{NaOH}$ as described by Katz et al. (1984).

The surface charge of the cellulosic fibres was determined by the polyDADMAC adsorption method (Wågberg et al. 1989).

Fibre treatment. The CTMP pulp was hot disintegrated at $85{ }^{\circ} \mathrm{C}$ in distilled water before sheet preparation according to SCAN M10: 77

The chemical pulp was reslushed in distilled water at room temperature for 30000 revolutions according to SCAN C: 1865. After reslushing, the fibres were combined in different ratios to a solid concentration of $5 \mathrm{~g} / \mathrm{l}$ and the $\mathrm{pH}$ was adjusted to $\mathrm{pH}$ 6. The salt concentration was kept constant at $0.01 \mathrm{M}$. The pulps were mixed to different compositions to clarify the influence of the chemimechanical pulp on paper properties. The amount of CTMP in the various compositions was 20, 60, 70, 80, and 100\%. Pulp mixtures containing 20, 80 , and $100 \%$ CTMP were subjected to polyelectrolyte multilayers treatment and prepared into sheets.

Sheet preparation and paper testing. After adsorption of each polyelectrolyte layer (3 layers in total), sheets with a grammage of $150 \mathrm{~g} / \mathrm{m}^{2}$ were made in a Rapid Köthen sheet former from Paper Testing Instruments (PTI), Pettenbach, Austria. Sheets were formed following ISO/DIS 5269-2 after thorough fibre dispersion with the aid of vigorous aeration. The sheets were then pressed at $100 \mathrm{kPa}$ and dried at $94{ }^{\circ} \mathrm{C}$. A comparison between several investigations with the same type of PEM treatment showed a high reproducibility and repeatability, and the difference in achieved strength properties between different experimental investigations was below $10 \%$. Ocular inspection of the sheets also showed that there was a detectable influence of the PEM treatment of the formation of the sheets.

Paper testing. Tensile testing was conducted according to SCAN P: 67. Grammage, thickness and density were evaluated according to SCAN C 28:76. Scott Bond testing was conducted according to Tappi 833 pm-94.

\section{Results and Discussion}

\section{Adsorption measurements with SPAR}

In order to investigate the possibility to form polyelectrolyte multilayers (PEM) using starch and CMC, the adsorption of starch and CMC was tested with the aid of the SPAR equipment fitted with a $\mathrm{SiO}_{2}$ surface. The surfaces were exposed to cyclic treatments of cationic starch and anionic $\mathrm{CMC}$ solutions in $10^{-2} \mathrm{M} \mathrm{NaCl}$, with each treatment followed by a rinsing with a $10^{-2} \mathrm{M} \mathrm{NaCl}$ solution. The relative changes in reflectometer signal, $\Delta S / S$, for the adsorbed layers are shown in Fig 1. First, a stable baseline was established with a $10^{-2} \mathrm{M} \mathrm{NaCl}$ solution before starting addition of the first polyelectrolyte, i.e., the cationic starch. A rinsing step was introduced after the starch adsorption, followed by CMC adsorption and a second rinsing step. This was repeated for three more layers with rinsing of an electrolyte solution between each layer. The adsorption results, using the SPAR equipment, revealed the possibility of building polyelectrolyte multilayers with cationic starch and $\mathrm{CMC}$ at $\mathrm{pH} 6$ in $0.01 \mathrm{M}$ $\mathrm{NaCl}$. With the support from earlier published data (Decher and Schlenoff 2003) these results also clearly indicate that the silica surface can be recharged with each polyelectrolyte treatment despite the low charge density of the two polyelectrolytes.

Scaling the $\left(S-S_{o}\right) / S_{o}$ values for each treatment by the appropriate $d n / d c$-value estimates the relationship between the adsorbed amounts in each bilayer. The ratio between the amount of CMC and starch in the first bilayer was 1.5 and 0.85 in the second bilayer. Fig 1 also shows that steady state, i.e., a constant charge ratio between the two polyelectrolytes in each bilayer, was not

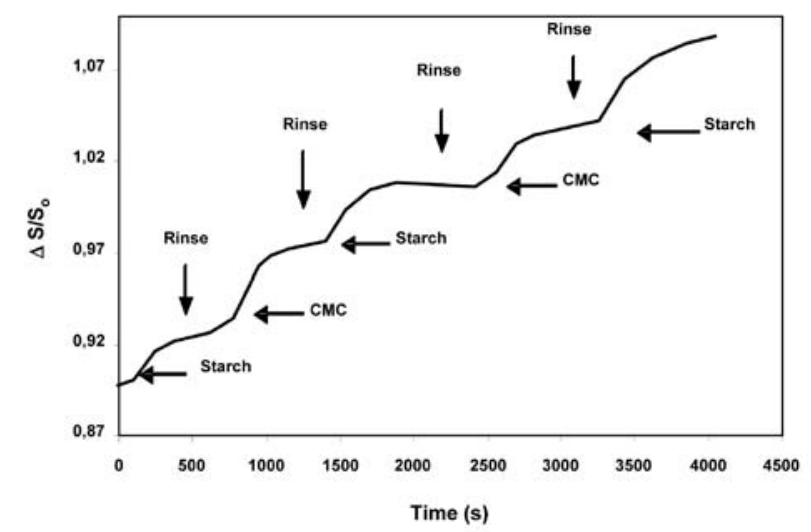

Fig 1.The change in reflectometer signal upon adsorption of cationic potato starch (CS) onto a $\mathrm{SiO}_{2}$ surface followed by adsorption of $\mathrm{CMC}$. This procedure is then repeated until five layers of the polyelectrolytes are created. A rinsing step with $10^{-2} \mathrm{M} \mathrm{NaCl}$ solution between each polyelectrolyte treatment step was performed in order to remove any excess of starch or CMC. 
reached within the first layers. This is in accordance with earlier work (Decher and Schlenoff 2003), where it was shown that a constant ratio between the two polyelectrolytes was not reached until 5-7 bilayers had been created.

These results also show that the charge density of these polyelectrolytes is sufficient for PEM formation on $\mathrm{SiO}_{2}$ surfaces and therefore it was decided to investigate if multilayers with these polyelectrolytes also could be formed on fibre.

\section{Multilayer formation on fibres}

Based on the SPAR results, it was necessary to investigate multilayer adsorption onto fibres. Earlier work showed the possibility to adsorb $1-2 \%$ of moderately charged cationic starch, i.e., with D.S from 0.03 to 0.06 , onto bleached chemical fibres before consuming the fibre charges (Wågberg and Björklund 1993). The adsorption of cationic starch was determined for the unbleached chemical fibres beaten to $22 \mathrm{SR}$, with the adsorption isotherm for the 0.065 D.S. cationic starch shown in Fig 2.

From the data in Fig 2, the fibre surface of the unbleached pulp starts to be saturated at a loading of $\sim 22 \mathrm{mg} / \mathrm{g}$, but an excess amount, up to $40 \mathrm{mg} / \mathrm{g}$, could be adsorbed. This type of saturation adsorption is very common for this type of system with polydisperse polyelectrolytes and porous materials (Wågberg et al. 1987) where it was also shown that the change of the slope in the isotherm was a clear indication of a saturation of the fibre surface by the polyelectrolyte. Compared to the bleached chemical pulp,

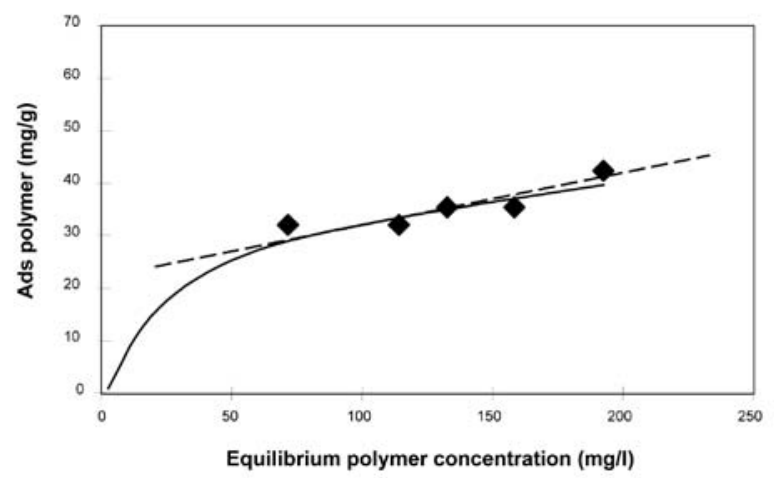

Fig 2. Adsorption of cationic potato starch (CS) with a D.S of 0.065 at $\mathrm{pH}=6$ and $0.01 \mathrm{M} \mathrm{NaCl}$ onto the unbleached chemical pulp beaten to $22 \mathrm{SR}$

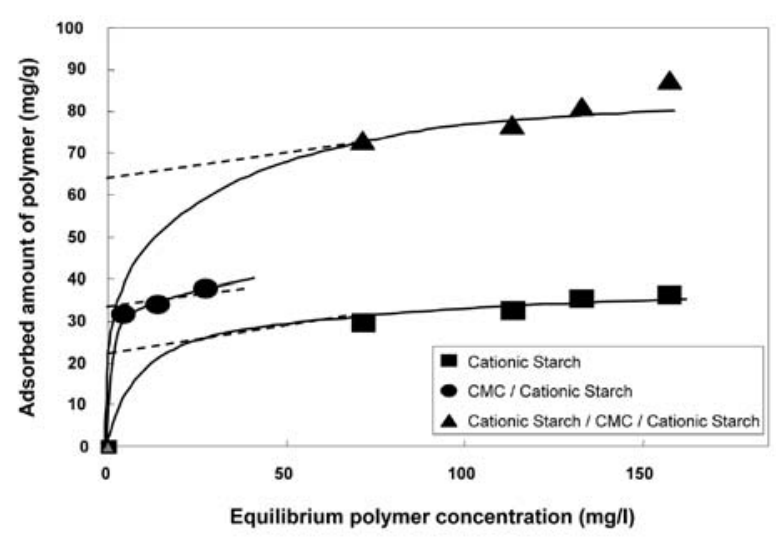

Fig 3. Isotherms of three layers of cationic starch, CMC and cationic starch adsorbed in $0.01 \mathrm{M} \mathrm{NaCl}$ at pH 6 on the unbleached chemical pulp beaten to $22 \mathrm{SR}$. The dotted lines show the extrapolation to zero polymer concentration, which was the dosage used for the preparing sheets. more cationic starch adsorbed onto the unbleached pulp due to the higher surface charge of this pulp. As known from earlier investigations (Wågberg et al. 1988, Aksberg and Ödberg 1990), the excess adsorbed amount oversaturated the fibre surface, making it possible to adsorb an anionic polyelectrolyte on top of the starch layer (Decher and Schlenoff 2003, Wågberg et al. 1988, Sandberg, and Andreasson 2000, Reynolds 1980). Further adsorption isotherms, seen in Fig 3, were determined in order to measure the adsorbed amount in consecutive layers.

In Fig 3 it is shown that the adsorption of CMC in the second layer was lower than the adsorption of starch in the first layer, i.e., around $17 \mathrm{mg} / \mathrm{g}$ compared to $22 \mathrm{mg} / \mathrm{g}$. This is somewhat different from the results found in the SPAR measurements, where there was a higher adsorption of CMC compared with starch in the first layer. There might naturally be several explanations for this difference, but most probably the difference is caused by the difference in geometry of the two types of surfaces. The $\mathrm{SiO}_{2}$ surfaces are flat and the starch molecules will quickly start to limit the packing of the molecules on the surface for purely geometrical reasons. This will lead to a rather extended adsorbed layer of the starch on the flat surfaces allowing for an efficient interaction with the $\mathrm{CMC}$ in the second layer. Fibre surfaces, on the other hand, are known to have roughness of the order of $30 \mathrm{~nm}$ to parts of a mm due to the fibril structure of the surface. Amylopectin is known to have very large dimensions for a polyelectrolyte and the typical cross-dimension of this cylindrical polyelectrolyte is of the order of $30 \mathrm{~nm}$ (Björklund and Wågberg 1995). This means that the starch will be "hidden" within the surface structure of the fibres. In turn this would make the binding of the CMC in the second layer a bit more difficult compared to a flat surface. Needless to say, further experiments are needed to test this hypothesis.

The amount of starch adsorbed in the third layer was about the same as in the first layer, which was in accordance with the adsorption results from SPAR. Despite the difference in ratio between the adsorbed amounts in the first bilayer, it was concluded that the trends in the adsorption were similar for the two methods.

\section{Influence of beating on PEM formation}

Previous work has shown that fines have a large influence on the saturation adsorption of the polyelectrolyte (Wågberg and Björklund 1993). It therefore became important to investigate the extent to which beating affected polyelectrolyte multilayer formation on the fibres. The procedure for forming polyelectrolyte multilayers was repeated for pulps with different degrees of beating with the results, in terms of the total adsorption for the different degrees of beating and the adsorption in each individual layer, summarised in Table 1. A linear increase in adsorption was exhibited for each layer and for each level of beating, such that beating the pulp to 33 SR tripled the starch adsorption both in layer 1 and 3 compared to the unbeaten fibres. However, a more careful examination of Table 1 showed that beating the fibres 
to $22 \mathrm{SR}$ increased the adsorption in all three layers by a factor close to three.

Further beating the fibres to 33 SR only increased the adsorption in the first adsorbed layer (cationic starch), whereas the adsorption in the second and third layers was similar.

For the unbeaten fibres the ratio between layers 1-3 is $1.0: 1.0: 1.0$, whereas it is $1.0: 0.8: 1.5$ for the 22 SR pulp and 1:0.5:2.1 for the $33 \mathrm{SR}$ pulp. This shows that a significant amount of charges from the cationic starch is not, to the same extent as for the unbeaten fibres, available to the charges of the CMC in the second layer for the beaten pulps. In turn, this could be an indication of a different conformation of the cationic starch on the surface of the beaten fibres and fibrils from these fibres. It could also be an indication that the cationic starch will decrease the surface available for the CMC molecules in the second layer. This could, for example, be brought about by an aggregation of fines and a collapsing of fibrils on the surface of fibres by the cationic starch. Since there is no obvious reason why the adsorption conformation of the starch should be different for the differently treated fibres, this second explanation seems most likely. The fact that more starch (in $\mathrm{mg} / \mathrm{g}$ ) is adsorbed compared with the CMC can most probably be linked to lower charge of the starch.

All these results nevertheless show that a combination of beating and PEM treatment could be a very useful way of reaching very high levels of polymer adsorption in these unbleached chemical fibres. However, only the pulp beaten to 22 SR was chosen for further studies since it showed very good adsorption capacity and a higher degree of beating would probably result in a too high densification of the sheets, which would be disadvantageous from a bending stiffness point of view.

The total charge and surface charge of the CTMP selected are very similar to the properties of the 22 SR chemical pulps, seen in Table 2, and therefore only the multilayer adsorption to the chemical pulp was investigated.

\section{Strength of sheets prepared with Starch/CMC multilayer treatment}

Both SPAR measurements and adsorption measurements to fibres showed the formation of PEMs, and therefore sheets were prepared from fibres treated with multilayers

Table 1. Results for the total adsorption of polyelectrolytes on the unbleached chemical pulp with different degrees of beating in three consecutive layers. The figures in brackets correspond to the adsorption in each layer.

\begin{tabular}{lccc}
\hline Number of layers & $\begin{array}{c}\text { Unbeaten sulphate } \\
(\mathbf{m g} / \mathbf{g})\end{array}$ & $\begin{array}{c}\text { Beaten sulphate } \\
\text { SR 22 }(\mathbf{m g} / \mathbf{g})\end{array}$ & $\begin{array}{c}\text { Beaten sulphate } \\
\text { SR 33 }(\mathbf{m g} / \mathbf{g})\end{array}$ \\
\hline 1 (starch) & $8(8)$ & $22(22)$ & $31(31)$ \\
2 (CMC) & $16(8)$ & $39(17)$ & $45(14)$ \\
3 (starch) & $24(8)$ & $65(26)$ & $74(29)$ \\
\hline
\end{tabular}

Table 2. Total charge and surface charge for the pulps used for sheet preparation.

\begin{tabular}{lcc}
\hline Pulp & Total charge $(\mu \mathrm{eq} . / \mathrm{g})$ & Surface charge $(\mu \mathrm{eq} . / \mathrm{g})$ \\
\hline CTMP & 99.5 & 13.8 \\
Chemical pulp with 22 SR & 99.2 & 18.4 \\
\hline
\end{tabular}

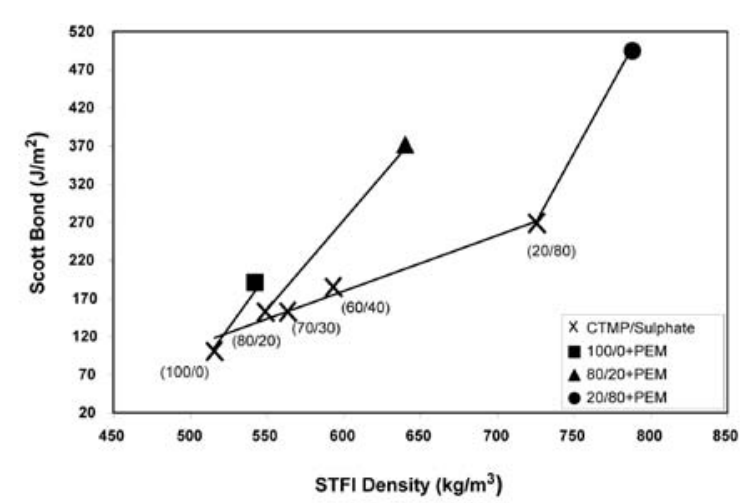

Fig 4. Scott Bond value as a function of sheet density for sheets made from CTMP and unbleached chemical softwood beaten to 22 SR. Different mixtures, both with and without PEM (polyelectrolyte multilayers) of cationic starch and CMC are presented.

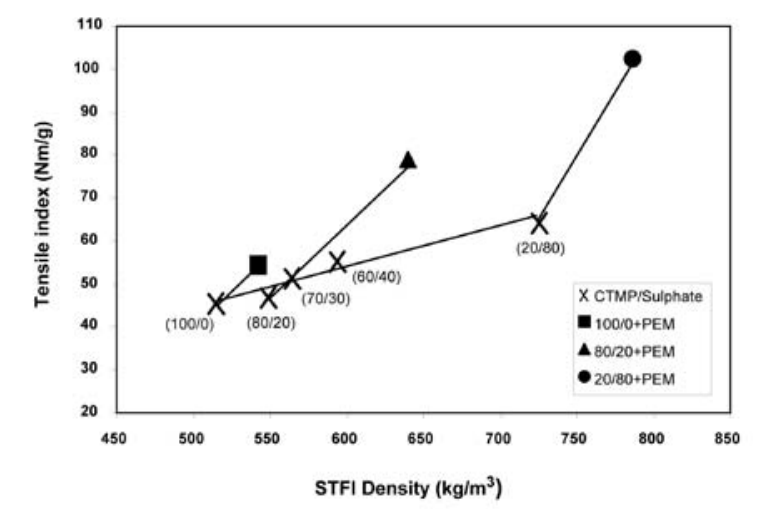

Fig 5. Tensile index for sheets made from CTMP and unbleached chemical pulp beaten to 22 SR. Sheets from various mixtures, with or without PEM treatment of cationic starch and CMC, were prepared having different densities.

of cationic starch and CMC in order to establish whether these chemicals are able to increase paper strength. Different mixtures of CTMP and unbleached chemical pulp beaten to 22 SR were used as a reference, and the effect of PEM treatment on various paper properties is compared in Figs 4-7.

Figs 4 and 5 show that there is an increase in density, Scott Bond, and tensile index as the amount of chemical pulp in the furnish is increased. However, it is important to increase the z-strength for a typical packaging board without increasing the sheet density. It would therefore be ideal to increase the Scott Bond value without increasing the density, which can almost be achieved with the polyelectrolyte multilayer treatment. PEM treatment significantly increases both the Scott Bond value and tensile index, while inducing only a small change in density. Thus, PEM treatment yields higher strength than could be achieved by increasing the amount of sulphate pulp, only without significantly increasing the density. It is possible to increase the tensile index and Scott Bond value with polyelectrolyte multilayer treatment beyond the limits that can be achieved with a pure chemical pulp. This means that a combination of a mixture of a very bulky CTMP and a chemical pulp treated with polyelectrolyte multilayers could produce sheets with sufficient structural stiffness compared to other combinations of CTMP and unbleached kraft pulp without polyelectrolyte multilayer treatment.

It is necessary to know how the tensile stiffness index changes with density for the different treatments, i.e., 
increased amount of sulphate pulp or polyelectrolyte multilayer treatment, in order to determine the structural stiffness of the sheets. Fig 6 shows a linear relationship between density and tensile stiffness for all the sheets shown in Figs 4 and 5. The bending stiffness index is then calculated as:

$$
S_{b}=\frac{1}{12}\left(\frac{\boldsymbol{E}}{\rho}\right) \frac{\boldsymbol{1}}{\rho^{2}} \quad\left(\mathrm{Nm}^{7} / \mathrm{kg}^{3}\right)
$$

$$
\text { where } \begin{aligned}
\mathrm{E} / \rho & =\text { tensile stiffness index }(\mathrm{Nm} / \mathrm{kg}) \\
\rho & =\text { density }\left(\mathrm{kg} / \mathrm{m}^{3}\right)
\end{aligned}
$$

These calculated values compare how the structural stiffness changes with the different treatments. A comparison of the PEM treatment of sheets with a $(20 / 80)$ mixture of CTMP/unbleached sulphate to an $(80 / 20)$ mixture shows that at a similar Scott Bond value (270 $\left.\mathrm{J} / \mathrm{m}^{2}\right)$ the sheets with an $(80 / 20)$ mixture become stiffer, having a $S_{b}$-value of 1.42 compared to the $(20 / 80)$ mixture, which has a $S_{b}$-value of 1.17 . Thus, the $80 / 20$ mixture with polyelectrolyte multilayer treatment has a $21 \%$ higher bending stiffness index compared with the 20/80 mixture at a similar Scott Bond value. It is likely that even bulkier CTMP could produce a better increase in $S_{b}$ at a given Scott Bond value.

The light-scattering ability of the paper at a certain density is an important parameter especially for printing papers. In Fig 7 it is seen that the polyelectrolyte multilayer treatment significantly improves the tensile strength without degrading light-scattering properties as much as the addition of chemical pulp. This shows that the polyelectrolyte multilayer treatment could also be a very promising technology for treatment for printing papers containing mechanical pulps and chemical pulps.

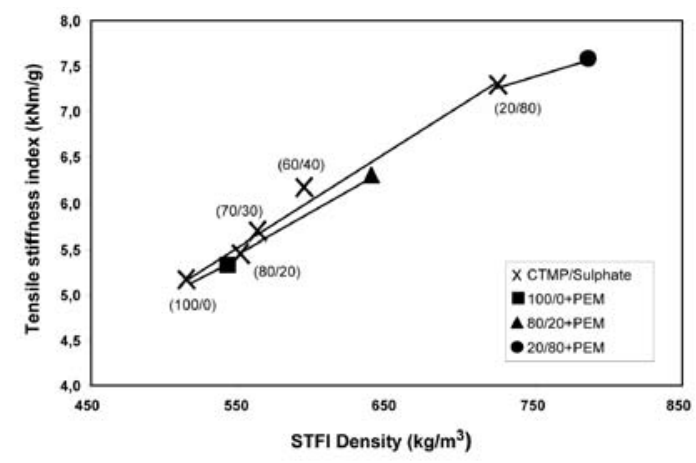

Fig 6. Tensile stiffness index for sheets made from various mixtures of CTMP and unbleached chemical pulp beaten to 22 SR, both without and with PEM treatment.

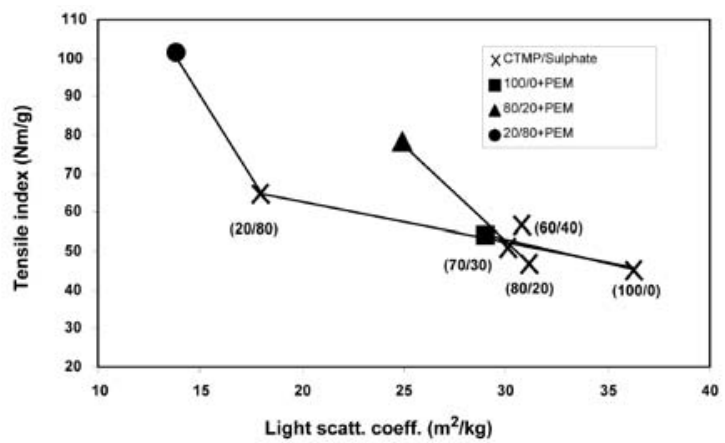

Fig 7. Tensile index as a function of light-scattering coefficient for sheets from CTMP and unbleached chemical pulp beaten to 22 SR without and with PEM (polyelectrolyte multilayer) treatment from cationic starch and CMC.

\section{Conclusions}

A new application for fibre surface engineering has been presented by which the fibres are consecutively treated with cationic starch and anionic CMC to form polymeric multilayers on the fibres. Initial reflectometer measurements showed that the selected polyelectrolytes really formed multilayers on surfaces of similar charge to wood fibres.

Polyelectrolyte multilayer treatment of the different pulp mixtures was compared to untreated mixtures, resulting in a large increase in the Scott Bond value and tensile index of the sheets. This increase in Scott Bond value and tensile index was achieved at significantly lower increases in density compared to an increase of the chemical pulp in the fibre mixture. Results also show that there is a common relationship between density and tensile stiffness index for all tested sheets. However, comparing sheets without polyelectrolyte multilayer treatment and sheets with polyelectrolyte multilayer treatment at the same Scott Bond value showed that the polyelectrolyte multilayer treated sheets had a specific bending stiffness index $21 \%$ higher than that of the untreated sheets.

The results also give clear indication that the application of the polyelectrolyte multilayer technology could also improve the tensile index without sacrificing as much in light scattering as an addition of chemical pulp would produce.

It can hence be concluded that the treatment of the fibres with assemblies of polyelectrolyte multilayers is a new way of functionalising fibre surfaces and for possible applications ranging from hygiene products to paperboard.

\section{Acknowledgement}

The author would like to thank Stora Enso for help with supplying pulp and for cooperating in this project, especially Hans Hallgren and Mats Fredlund for their valuable comments and discussions

\section{Literature}

Aksberg, R. and Ödberg, L. (1990): Adsorption of an anionic polyacrylamide on cellulosic fibres pre-adsorbed cationic polyelectrolytes, Nordic Pulp Paper Res. J. 4, 168.

Bley, L. and Kastner, M. (1992): Paper presented at SPCI-ATICELCA 92, European Pulp and Paper Week: New Available Techniques and Current Trends, Paper Control 19-22 May 1992, Bologna, Italy.

Björklund, M. and Wågberg, L. (1995): Flocculation of cellulosic fibres following addition of cationic starch, Colloids Surfaces A Phys. Chem. Eng. Asp. 105, 199. Dabros, T. and van de Ven, T.G.M. (1983): Colloid Polym. Sci., 261, 694.

Decher, G. (1997): Fuzzy Nano-asssemblies: Toward Layered Polymeric Multicomposites, Science, 277, 1233.

Decher, G. and Schlenoff, J. (2003): Multilayer Thin Films, ISBN: 3-527-30440-1. Dijt, J. C., Cohen Stuart, M. A., Hofman J. E. and Fleer, G.J. (1990): Kinetics of polymer adsorption in stagnation point flow, Colloids Surfaces, 51, 141. Dijt, J. C., Cohen Stuart, M. A. and Fleer G.J. (1994): Reflectometry as a tool for adsorption studies, Adv. Coll. Interf. Sci., 50, 79.

Galinsky, G. and Burchard, W. (1997): Starch Fractions as Examples for Nonrandomly Branched Macromolecules. 3. Angular Dependence in Static Light Scattering, Macromolecules, 30:15, 4445. 
Gärdlund, G., Wågberg, L. and Gernandt, R. (2003): Polyelectrolyte complexes for surface modification of wood fibres: II. Influence of complexes on wet and dry strength of paper, Colloids Surfaces A: Phys.chem.I Eng. Aspects, 218:1-3, 137.

Hedborg, F and Lindström, T. (1993): Adsorption of cationic starch on bleached softwood cellulosic fibres, Nordic Pulp Paper Res. J. 8:2, 258.

Hoogeveen, G.N., Cohen Stuart, M.A. and Fleer, G.J. (1996): Polyelectrolyte Adsorption on Oxides: I. Kinetics and Adsorbed Amounts, J. Colloid Interface Sci. $182: 1,133$

Katz, S., Beatson, RP. and Scallan AM. (1984): The determination of strong and weak acidic groups in sulphite pulps, Svensk Papperstidning, 87:6, R48.

Marton, J. (1980): The role of surface chemistry in fines-cationic starch interactions, Tappi, 59:4 87.

Niskanen, K., Kajanto, I. and Pakarinen, P. (1998): Papermaking Science and Technology 16: Paper Physics: Paper structure. FAPET, Helsinki, chapter 1, 13. Marton, J. (1996): Dry-strength additives. Chapter 6 in Paper Chemistry, Edited J. C. Roberts. ISBN 0751402362

Reynolds, W.F. (1980): Dry strength additives, Tappi Press, Atlanta.

Sandberg, S. and Andreasson, B. (2000): Swedish Patent Application SE 0001268-2

Sun, Y., Zhang, X., Sun, C., Wang, B. and Shen, J. (1996): Fabrication of ultrathin film containing bienzyme of glucose oxidase and glucoamylase based on electrostatic interaction and its potential application as a maltose sensor, Macromolecules Chem. Phys. 197, 147.

Sundholm, J. (1999): Papermaking Science and Technology: Mechanical pulping, FAPET, Helsinki, Chapter 4, ISBN: 952-5216-05-5.

Swerin, A. and Wågberg, L. (1994): Use of HPLC-methodology to characterize cationic polymers used in the paper industry, Nordic Pulp Paper Res. J. 9(1), 18.
Wågberg, L. and Kolar, K. (1996): Adsorption of cationic starch on fibres from mechanical pulps, Ber. Bunsenges. Phys. Chem. 100(6), 984.

Wågberg, L. Winter, L, Ödberg, L. and Lindström, T. (1987): On the charge stoichiometry upon adsorption of a cationic polyelectrolyte on cellulosic materials, Colloids Surfaces, 27, 163.

Wågberg, L. and Forsberg, S. (1998): International patent application WO $00 / 32702$

Wågberg, L, Forsberg, S, Johansson, A. and Juntti, P. (2002): Engineering of fibre surface properties by application of the polyelectrolyte multilayer concept. Part I: modification of paper strength, J. Pulp Paper Sci. 28, 222.

Wågberg, L. and Nygren, I. (1999): The use of stagnation point adsorption reflectometry to study molecular interactions relevant to papermaking chemistry, Colloids Surfaces A: Phys.chem. Eng. Aspects, 159:1, 3.

Wågberg, L., Pettersson, G. and Notley, S. (2004): Adsorption of bilayers and multilayers of cationic and anionic co-polymers of acrylamide on silicon oxide, J. Colloid Interface Sci. In Press, Corrected Proof.

Wågberg, L., Ödberg, L. and Glad-Nordmark, G. (1989): Charge determination of porous substrates by polyelectrolyte adsorption. Nordic Pulp Paper Res. J. 2:1 71.

Wågberg, L. and Björklund, M. (1993): Adsorption of cationic potato starch on cellulosic fibres, Nordic Pulp Paper Res. J. 8:4, 399.

Wågberg, L., Ödberg, L. and Lindström, T. (1988): Kinetics of adsorption and ion exchange reactions during adsorption of cationic polyelectrolytes on cellulosic fibres, J. Colloid Interface Sci. 123:1, 281.

Manuscript received August 24, 2005 Accepted December, 2005 